\title{
Serum Fertility Hormonal Levels In Malaria Infected Symptomatic HIV Male Subjects In Nnewi, South Eastern Nigeria.
}

\author{
${ }^{1}$ Ezeugwunne I.P., ${ }^{2}$ Onyenekwe C.C, ${ }^{3}$ Ifeanyichukwu M., \\ ${ }^{1}$ Meludu S.C, ${ }^{3}$ Chukwuanuku R, C. \\ 1.Department of Human Biochemistry; 2.Department of Chemical Pathology; 3.Department of Immunology, \\ College of Health Sciences, NnamdiAzikiwe University, Nnewi, Anambra State, Nigeria.
}

\begin{abstract}
The present study was design to determine the fertility hormonal levels of Luteinizing hormone (LH), Follicle stimulating hormone (LH), Progesterone, Testosterone, Proactin, Estrogen and Cortisol in malaria infected symptomatic HIV stage 11 seropositive male participants aged between 18 and 60 (42.13) years were randomly recruited for this study. Based on World Health Organisation (WHO) criteria for staging HIV, the participants were grouped as follows: 138 symptomatic HIV stage 11 infected male participants, 69 of them had malaria co-infection and 136 HIV seronegative male participants, 68 of them also had malaria co-infection. Blood samples were collected from the participants for the determination of HIV status by Immunochromatography and Immunoprecipitin methods, malaria parasite detection by thick and thin film method. The fertility hormones were also determined by Enzyme Linked Immunosorbent Assay (ELISA) methods. The result showed that the serum FSH, Progesterone, Testosterone, Estrogen and Cortisol levels were significantly different when compared amongst the groups ( $p<0.05$, in each case). Testosterone levels also showed significantly lower values in malaria infected and malaria uninfected symptomatic HIV stage 11 participants not on ART (in each case) compared with malaria infected and malaria uninfected HIV seronegative control participants $(p<0.05)$. The mean FSH levels were significantly different in malaria infected and malaria uninfected symptomatic HIV stage 11 participants not on ART (in each case) compared with malaria infected and malaria uninfected HIV seronegative control participants $(p<0.05)$. The implication of this finding is that HIV-malaria co infection has an effect on the release of LH, FSH and Cortisol levels in symptomatic HIV stage 11 participants.
\end{abstract}

\section{Introduction}

Fertility in men is the ability to make a fertile woman pregnant after an act of sexual intercourse (Hirsh, 2003; Brugh and Lipshultz, 2004). The sexual activity and the gonadal functions are mediated by the hypothalamicpituitary-gonadal axis, which is a closed loop system with feedback control from the testes (Xionget al, 2006; Van Den Boogaardet al, 2011).The fertility hormones that are vital for normal sexual activity are the Testosterone, Progesterone, Estrogen, Prolactin, Cortisol, Follicle Stimulating Hormone (FSH) and Luteinizing Hormone (LH). Disorders of the hypothalamus lead to hypogonadotropichypogonadism (Whitten, 2006). Also, both pituitary insufficiency and excess causes infertility (Grover et al, 2005). Infection such as HIV has been implicated to affect the endocrine system (Roof and Hall, 2000; Pransanthaiet al, 2007).

Human Immunodeficiency Virus (HIV) is a virus that causes Acquired Immunodeficiency symdrome (AIDS) (Doueket al, 2009). The majority of HIV infections are acquired through unprotected sexual relations. Complacency about HIV has been observed to play a key in HIV risk (UNAIDS, 2008). HIV and malaria co-infection has been implicated in Nigeria (Onyenekweet al, 2007). Fertility hormones such as LH (Burgoyne and Tan, 2008), FSH (Villetteet al, 1990)and Cortisol (Corcoron and Grinspoon, 1999) have been elevated in HIV disease while low Testosterone levels have been observed in HIV disease (Roof and Hall, 2000). HIV- related immunosuppression has been suggested to increase the rate of malaria infection and clinical malaria disease (Lauferet al, 2006). Plasmodiun.falciparum is the most common cause of malaria infection and is responsible for about $80 \%$ of all malaria cases, and is also responsible for about $90 \%$ of the deaths from malaria (Mendiset al, 2001).

Since most of the finding on the effect of HIV on fertility hormones documented were not observed in Nigeria. Again, Nigeria being an endemic area for malaria breeding, it is now necessary to assess the effect of HIV and malaria co-infection on the fertility hormones in symptomatic HIV infected subjects not on ART in Nigeria so to see if there will be differences in the results.

\section{Materials and methods}




\section{Subjects}

A total of 274 adult male participants aged between 18 and $60(42 \pm 13)$ years were randomly recruited at the Voluntary Counseling and Testing (VCT) Centre in NnamdiAzikiwe University Teaching Hospital (NAUTH), Nnewi, Nigeria. Based on World Health Organisation (WHO) criteria for staging HIV, the participants were grouped as follows: 138 symptomatic HIV (stage 11) infected male participants, 69 of them had malaria co-infection and $136 \mathrm{HIV}$ seronegative male participants, 68 of them also had malaria co-infection. $5 \mathrm{ml}$ of blood samples were collected from each of the participant and dispensed into EDTA tube for HIV screening by Immunoprecipitin and Immunochromatographic method. The malaria parasite density count was examined microscopically by thick and thin method. The serum from the remaining blood placed into a plain tube was used for the estimation of FSH, LH, Testosterone, Estrogen, Progesterone, Prolactin and Cortisol levels by ELISA method. The serum samples were stored at $-20^{\circ} \mathrm{C}$ until analysed. Informed consent was obtained from those who participated in the study. The NnamdiAzikiwe University Teaching Hospital Board of Ethical Committee approved the study design.

\section{Methods}

Detection of Antibodies to HIV-1 and HIV-2 in Human plasma.

Two different methods were used, namely, Abbott determine ${ }^{\mathrm{TM}} \mathrm{HIV}-1$ and HIV-2 kit, which is an in-vitro visually read immunoassay (Abbott Japan Co.Ltd.Tokyo, Japan) and HIV-1 and 2 STAT-PAK Assay kit, which is an Immunochromatographic test for the quantitative detection of antibodies to HIV-1 and HIV-2 in Human plasma (CHEMBIO Diagnostic system, Inc, New York, USA). For the Abbott determine ${ }^{\mathrm{TM}}$ HIV -1 and HIV-2 kit, the procedure described by the manufacturer was used for the analysis. Briefly, $50 \mu \mathrm{l}$ of participant serum samples separated from the corresponding whole blood samples in EDTA were applied to the appropriately labeled sample pad. After 15 minutes but not more than 60 minutes of sample application, the result was read. This method has inherent quality control that validates the results. For the Immunochromatographic method for HIV -1 and HIV-2, the procedure described by the manufacturer was used for the analysis. In brief, $5 \mathrm{ml}$ of participant's plasma was dispensed into the sample well in the appropriately labeled sample pad. Three drops of the buffer supplied by the manufacturer was added into the appropriately labeled sample pad. The results of the test were read at 10 minutes after the addition of the running buffer. This method has inherent quality control and validates the results.

\section{Thick and thin film as will be described by WHO (1995).}

Thick and thin films will be prepared for each participant's blood sample. The thin films were fixed with methanol and both thick and thin films were stained with Giemsa ( 1 in 10 dilution) for 10 minutes, after which they were examined microscopically with oil immersion (x 100) objective. The malaria parasite counting was done using the thick blood films while the thin blood films were used for species identification. Malaria parasites were counted according to the method of World Health Organisation (1995). 200 leukocytes were counted and if 10 or more parasites were identified, then the number of parasites per 200 leucocytes was recorded; but if after counting 200 leukocytes and 9 or less parasites identified then, 500 leukocytes was recorded. In each case the parasite count in relation to the leukocyte count was converted to parasite per microlitre of blood using this mathematical formular: Malaria parasite density $/ \mu \mathrm{l}=\quad$ number of parasites $\times 8000$

Number of leukocytes

Where 8000, is the average number of leukocyte per microlitre of blood, which is taken as the standard (WHO, 1995).

\section{CD4 $^{+}$T CELL Count by Flow Cytometry}

$200 \mathrm{ml}$ EDTA whole blood was collected into PARTEC test tubes (Rohren tube). Then $20 \mu \mathrm{l} \mathrm{ofCD} 4^{+} \mathrm{T}^{\circ}$ antibody was added into the tube. The contents were mixed and incubated in the dark for 15 minutes at roomtemperature. $800 \mathrm{ml}$ of CD4 buffer was gently added into the mixture and mixed gently. Then the Partec tube was plugged on the Cyflow counter and the $\mathrm{CD}^{+} \mathrm{T}$ cells were displayed as peaks and interpreted as figures.

\section{Estimation of LH by Randox Laboratories Limited, U.K}

Serum LH was estimated by Enzyme Linked Immunosorbent assay (ELISA). The procedure was as described by the manufacturer of the kit (Randox Laboratories Limited, UK); $50 \mu$ l of serum sample was added to appropriately labeled microtitre wells and $100 \mu \mathrm{l}$ Enzyme conjugated detection antibody was also added to the wells. The same procedure was performed for the standard as well as HIV negative control serum samples. They were incubated at room temperature for 45 minutes. The wells were washed 3 times with deionized water to removed unbound antibodies. 100 $\mu \mathrm{l}$ TMB reagent was added and well incubated in the dark for 20 minutes for the 


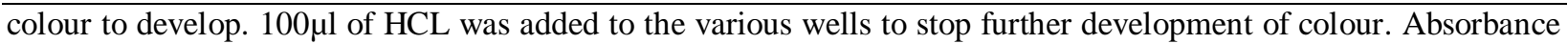
was read at 450nm using ELISA machine and deionized water served as blank. The test and control samples concentrations were extrapolated from the standard curve. The standard curve was plotted from the optical density values and concentrations of series of FSH standards $(0,5,15,50,100$ and $200 \mathrm{miu} / \mathrm{ml})$ provided by the manufacturer of the kit.

\section{Estimation of FSH by Randox Laboratories Limited, U.K}

Serum FSH was estimated by Enzyme Linked Immunosorbent assay (ELISA). The procedure was as described by the manufacturer of the kit (Randox Laboratories Limited, UK); $50 \mu$ l of serum sample was added to appropriately labeled microtitre wells and $100 \mu \mathrm{l}$ Enzyme conjugated detection antibody was also added to the wells. The same procedure was performed for the standard as well as HIV negative control serum samples. They were incubated at room temperature for 45 minutes. The wells were washed 3 times with deionized water to removed unbound antibodies. $100 \mu \mathrm{l}$ tetramethylbenzidine (TMB) reagent was added and well incubated at room temperature for 20 minutes for the colour to develop. 100 $\mu$ l of hydrochloric acid (HCL) was added to the various wells to stop further development of colour. Absorbance was read at 450nm using ELISA machine and deionized water served as blank. The test and control samples concentrations were extrapolated from the standard curve. The standard curve was plotted from the optical density (OD) values and concentrations of series of FSH standards (0, 5, $15,50,100$ and $200 \mathrm{miu} / \mathrm{ml}$ ) provided by the manufacturer of the kit.

\section{Estimation of Progesterone by Randox Laboratories Limited, U.K}

Serum Progesterone was estimated by Enzyme Linked Immunosorbent assay (ELISA). The procedure was as described by the manufacturer of the kit (Randox Laboratories Limited, UK); $25 \mu$ l of serum sample was added to appropriately labeled microtitre wells and $100 \mu$ l Progesterone Enzyme horseradish peroxidase conjugate reagent was added to the wells. Also, 50 $\mu$ l of rabbit anti-Progesterone reagent was added in each well. The same procedure was performed for the standard as well as HIV negative control serum samples. They were incubated at room temperature for 90 minutes. The wells were washed 3 times with deionized water to removed unbound antibodies. $100 \mu \mathrm{l}$ TMB reagent was added and well incubated at room temperature for 20 minutes for the colour to develop. $100 \mu \mathrm{l}$ of HCL was added to the various wells to stop further development of colour. Absorbance was read at 450nm using ELISA machine and deionized water served as blank. The test and control samples concentrations were extrapolated from the standard curve. The standard curve was plotted from the optical density values and concentrations of series of FSH standards $(0,0.5,3,10,25$ and $50 \mathrm{ng} / \mathrm{ml})$ provided by the manufacturer of the kit.

\section{Estimation of Testosterone by Randox Laboratories Limited, U.K}

Serum Testosterone was estimated by Enzyme Linked Immunosorbent assay (ELISA). The procedure was as described by the manufacturer of the kit (Randox Laboratories Limited, UK); $10 \mu$ l of serum sample was added to appropriately labeled microtitre wells and $100 \mu \mathrm{l}$ Enzyme conjugated detection antibody was also added to the wells. Also, $5 \mu \mathrm{l}$ of rabbit anti-Testosterone reagent was added in each well. The same procedure was performed for the standard as well as HIV negative control serum samples. They were incubated at $37^{\circ} \mathrm{C}$ for 90 minutes. The wells were washed 3 times with deionized water to removed unbound antibodies. 100 $\mu$ TMB reagent was added and well incubated at room temperature for 20 minutes for the colour to develop. 100 $\mu$ l of HCL was added to the various wells to stop further development of colour. Absorbance was read at 450nm using ELISA machine and deionized water served as blank. The test and control samples concentrations were extrapolated from the standard curve. The standard curve was plotted from the optical density values and concentrations of series of FSH standards $(0,0.1,0$. $5,2,6$ and $18 \mathrm{ng} / \mathrm{ml}$ ) provided by the manufacturer of the kit.

\section{Estimation of Prolactin byRandox Laboratories Limited, U.K}

Serum Prolactin was estimated by Enzyme Linked Immunosorbent assay (ELISA). The procedure was as described by the manufacturer of the kit (Randox Laboratories Limited, UK); $50 \mu$ l of serum sample was added to appropriately labeled microtitre wells and $100 \mu \mathrm{l}$ Enzyme conjugate reagent was also added to the wells. The same procedure was performed for the standard as well as HIV negative control serum samples. They were incubated at room temperature for 45 minutes. The wells were washed 3 times with deionized water to removed unbound antibodies. 100 $\mu \mathrm{l} \mathrm{TMB}$ reagent was added and well incubated at room temperature for 20 minutes for the colour to develop. 100 $\mu$ l of HCL was added to the various wells to stop further development of colour. Absorbance was read at 450nm using ELISA machine and deionized water served as blank. The test and control samples concentrations 
were extrapolated from the standard curve. The standard curve was plotted from the optical density values and concentrations of series of FSH standards $(0,5,15,50,100$ and $200 \mathrm{ng} / \mathrm{ml})$ provided by the manufacturer of the kit.

\section{Estimation of Estradiol by Randox Laboratories Limited, U.K}

Serum Estradiol was estimated by Enzyme Linked Immunosorbent assay (ELISA). The procedure was as described by the manufacturer of the kit (Randox Laboratories Limited, UK); $25 \mu 1$ of serum sample was added to appropriately labeled microtitre wells and $100 \mu$ l Enzyme conjugated detection antibody was also added to the wells. Also, $5 \mu \mathrm{l}$ of rabbit anti- Estradiol reagent was added in each well. The same procedure was performed for the standard as well as HIV negative control serum samples. They were incubated at $37^{\circ} \mathrm{C}$ for 90 minutes. The wells were washed 3 times with deionized water to removed unbound antibodies. 100 $\mu 1$ TMB reagent was added and well incubated at room temperature for 20 minutes for the colour to develop. 100 $\mu$ l of HCL was added to the various wells to stop further development of colour. Absorbance was read at 450nm using ELISA machine and deionized water served as blank. The test and control samples concentrations were extrapolated from the standard curve. The standard curve was plotted from the optical density values and concentrations of series of FSH standards $(0,10,30$, 100 and $1000 \mathrm{pg} / \mathrm{ml}$ ) provided by the manufacturer of the kit.

\section{Estimation of Cortisol byRandox Laboratories Limited, U.K}

Serum Cortisol was estimated by Enzyme Linked Immunosorbent assay (ELISA). The procedure was as described by the manufacturer of the kit (Randox Laboratories Limited, UK); $20 \mu \mathrm{l}$ of serum sample was added to appropriately labeled microtitre wells and $200 \mu \mathrm{l}$ Enzyme conjugate reagent was also added to the wells. The same procedure was performed for the standard as well as HIV negative control serum samples. They were incubated at room temperature for 60 minutes. The wells were washed 3 times with deionized water to removed unbound antibodies. 100 $\mu \mathrm{l} \mathrm{TMB}$ reagent was added and well incubated at room temperature for 20 minutes for the colour to develop. 100 $\mu$ l of HCL was added to the various wells to stop further development of colour. Absorbance was read at $450 \mathrm{~nm}$ using ELISA machine and deionized water served as blank. The test and control samples concentrations were extrapolated from the standard curve. The standard curve was plotted from the optical density values and concentrations of series of FSH standards $(0,20,50,100,200,400$ and $800 \mathrm{ng} / \mathrm{ml})$ provided by the manufacturer of the kit.

\section{Statistical analysis}

The result of the analysis was statistically analysed. Students't-test and one way analysis of variance (ANOVA) were used to compare means. The analysis was performed with the use of Statistical Package for Social Sciences (SPSS) statistical software package, version 13.0. P $<0.05$ was considered statistically significant.

\section{Result}

Table 1: Mean $( \pm \mathrm{SD})$ serum fertility hormonal levels in malaria infected and malaria uninfected male symptomatic HIV (stage 11) participants on ARTand in malaria infected and malaria uninfected HIV seronegative participants.

\begin{tabular}{|c|c|c|c|c|c|c|c|c|}
\hline Variables & $\mathrm{MPD} / \mu \mathrm{l}$ & $\begin{array}{l}\mathbf{L H} \\
(\mathrm{miu} / \mathrm{ml})\end{array}$ & $\begin{array}{l}\text { FSH } \\
(\mathbf{m i u} / \mathrm{ml})\end{array}$ & $\begin{array}{l}\text { Progest- } \\
\text { erone } \\
(\mathbf{n g} / \mathbf{m l})\end{array}$ & $\begin{array}{l}\text { Testost- } \\
\text { erone } \\
(\mathrm{ng} / \mathrm{ml})\end{array}$ & $\begin{array}{l}\text { prolactin } \\
\text { (ng/ml) }\end{array}$ & $\begin{array}{c}\text { Estrogen } \\
(\mathrm{pg} / \mathrm{ml})\end{array}$ & $\begin{array}{l}\text { Cortisol } \\
\text { (ng/ml) }\end{array}$ \\
\hline $\begin{array}{l}\text { Symptomatic HIV } \\
\text { stage } 11 \\
\text { participants with } \\
\text { malaria }(n=69)\end{array}$ & $\begin{array}{l}561.54 \pm \\
404.42\end{array}$ & $\begin{array}{l}12.59 \pm \\
8.20\end{array}$ & $\begin{array}{l}12.70 \pm \\
8.69\end{array}$ & $\begin{array}{l}2.05 \pm \\
1.39\end{array}$ & $\begin{array}{l}2.59 \pm \\
1.90\end{array}$ & $\begin{array}{l}9.33 \pm \\
4.67\end{array}$ & $\begin{array}{l}54.66 \pm \\
23.92\end{array}$ & $\begin{array}{l}250.56 \pm \\
135.24\end{array}$ \\
\hline $\begin{array}{l}\text { Symptomatic HIV } \\
\text { stage } 11 \\
\text { participants } \\
\text { without malaria } \\
(\mathrm{n}=69)\end{array}$ & & $\begin{array}{l}9.72 \pm \\
6.93\end{array}$ & $\begin{array}{l}7.91 \pm \\
5.17\end{array}$ & $\begin{array}{l}2.63 \pm \\
1.57\end{array}$ & $\begin{array}{l}2.07 \pm \\
2.14\end{array}$ & $\begin{array}{l}10.33 \pm \\
3.90\end{array}$ & $\begin{array}{l}66.79 \pm \\
19.83\end{array}$ & $\begin{array}{l}226.90 \pm \\
122.53\end{array}$ \\
\hline $\begin{array}{l}\text { HIV seronegative } \\
\text { with malaria } \\
(\mathrm{n}=68)\end{array}$ & $\begin{array}{l}538.94 \pm \\
351.15\end{array}$ & $\begin{array}{l}9.33 \pm \\
6.06\end{array}$ & $\begin{array}{l}8.54 \pm \\
5.25\end{array}$ & $\begin{array}{l}1.14 \pm \\
0.93\end{array}$ & $\begin{array}{l}3.37 \pm \\
2.24\end{array}$ & $\begin{array}{l}8.49 \pm \\
3.25\end{array}$ & $\begin{array}{l}51.10 \pm \\
37.68\end{array}$ & $\begin{array}{l}147.70 \pm \\
63.57\end{array}$ \\
\hline HIV seronegative & & $9.56 \pm$ & $11.53 \pm$ & $1.09 \pm$ & $4.80 \pm$ & $9.39 \pm$ & $31.14 \pm$ & $130.02 \pm$ \\
\hline
\end{tabular}


Serum Fertility Hormonal Levels In Malaria Infected Symptomatic HIV Male Subjects In Nnewi, South

Eastern Nigeria.

\begin{tabular}{|l|l|l|l|l|l|l|l|l|}
\hline $\begin{array}{l}\text { without malaria } \\
(\mathrm{n}=68)\end{array}$ & & 7.16 & 7.58 & 1.19 & 1.75 & 3.34 & 18.20 & 68.22 \\
\hline $\mathrm{F}(\mathrm{p})$ value & $\begin{array}{l}0.121 \\
>0.05\end{array}$ & $\begin{array}{l}3.18 \\
>0.05\end{array}$ & $\begin{array}{l}4.34 \\
<0.05\end{array}$ & $\begin{array}{l}22.89 \\
<0.05\end{array}$ & $\begin{array}{l}4.68 \\
<0.05\end{array}$ & $\begin{array}{l}2.66 \\
>0.05\end{array}$ & $\begin{array}{l}42.49 \\
<0.05\end{array}$ & $\begin{array}{l}22.83 \\
<0.05\end{array}$ \\
\hline $\mathrm{tIp}^{\mathrm{a}}$ & ---- & 0.124 & 0.499 & 0.111 & 0.570 & 0.526 & 0.008 & 0.704 \\
\hline $\mathrm{tIp}^{\mathrm{b}}$ & 0.012 & 0.045 & 0.005 & 0.000 & 0.015 & 0.607 & 0.000 & 0.000 \\
\hline $\mathrm{tIp}^{\mathrm{c}}$ & ---- & 0.102 & 0.832 & 0.000 & 0.647 & 1.000 & 0.000 & 0.000 \\
\hline $\mathrm{tIp}^{\mathrm{d}}$ & ---- & 0.985 & 0.507 & 0.000 & 0.000 & 0.016 & 0.000 & 0.000 \\
\hline $\mathrm{tIp}^{\mathrm{e}}$ & ---- & 0.999 & 0.048 & 0.000 & 0.000 & 0.427 & 0.000 & 0.000 \\
\hline $\mathrm{tIp}^{\mathrm{d}}$ & ---- & 0.997 & 0.043 & 0.993 & 0.985 & 0.378 & 0.045 & 0.375 \\
& & & & & & & & \\
\hline
\end{tabular}

Key: $F(p)$ value - symptomatic HIV stage 11 with and without malaria infection and HIV seronegative with and without malaria infection all compared (using ANOVA).

tIp ${ }^{\text {a }}$ symptomatic HIV stage 11 with and without malaria infection compared (using student's t-test).

tIp $^{\mathrm{b}}$ - symptomatic HIV stage 11 with malaria infection compared with HIV seronegative with malaria infection (using student's t-test).

$\operatorname{tIp}^{\mathrm{c}}$ - symptomatic HIV stage 11 with malaria infection compared with HIV seronegative without malaria infection (using student's t-test).

tIp ${ }^{d}$ - symptomatic HIV stage 11 without malaria infection compared with HIV seronegative with malaria infection (using student's t-test).

tIp $^{\mathrm{e}}$ - symptomatic HIV stage 11 without malaria infection compared with HIV seronegative without malaria infection (using student's t-test).

$\mathrm{tIp}^{\mathrm{f}}$-HIV seronegative with malaria infection compared HIV seronegative without malaria (using student's t-test).

The table 1 showed mean $( \pm \mathrm{SD})$ fertility hormonal levels in male symptomatic HIV stage 11 with and without malaria infection all compared. The result showed that there was statistically significant difference in FSH (miu/ml), Progesterone $(\mathrm{ng} / \mathrm{ml})$, Testosterone $(\mathrm{ng} / \mathrm{ml})$, Estrogen $(\mathrm{pg} / \mathrm{ml})$ and Cortisol $(\mathrm{ng} / \mathrm{ml})$ levels respectively compared amongst the groups above ( $<<0.05$, in each case). However, the mean $( \pm \mathrm{SD}) \mathrm{LH}(\mathrm{miu} / \mathrm{ml})$ and Prolactin $(\mathrm{ng} / \mathrm{ml})$ levels compared among groups above showed no significant difference ( $>0.05$, in each case).

The within groups comparison showed that the observed mean $( \pm \mathrm{SD})$ serum levels of FSH; $12.70 \pm 8.69$ and Cortisol $250 \pm 135.24$ observed in symptomatic HIV stage 11 with malaria were significantly higher compared with the corresponding values, FSH; 7.91 \pm 5.17 and Cortisol; $226.90 \pm 122.53$ observed in symptomatic HIV stage 11 without malaria infection. Also, the mean $( \pm \mathrm{SD})$ level of Estrogen; 54.66 \pm 23.92 , observed in symptomatic HIV stage 11 with malaria was significantly lower than the mean Estrogen; $66.79 \pm 19.83$ observed in symptomatic HIV stage 11 without malaria $(\mathrm{p}<0.05)$. However, the observed mean $( \pm \mathrm{SD})$ serum levels of $\mathrm{LH} ; 12.59 \pm 8.20$, Progesterone; $2.05 \pm 1.39$, Testosterone; $2.59 \pm 1.90$ and Prolactin; $9.33 \pm 4.67$ in symptomatic HIV stage 11 with malaria were significantly not different from the corresponding values, LH 9.72 \pm 6.93 , Progesterone; $2.63 \pm 1.57$, Testosterone; $2.07 \pm 2.04$ and Prolactin; $10.33 \pm 3.90$ in HIV stage 11 without malaria infection ( $>>0.05$, in each case). Mean ( \pm SD) LH 12.59 \pm 8.20 , FSH; 12.70 \pm 8.69 , Progesterone 2.05 \pm 1.39 and Cortisol $205.56 \pm 135.24$ respectively serum concentration observed in symptomatic HIV stage 11 with malaria were significantly higher than the values LH; 9.33 \pm 6.06 , FSH; 8.54 \pm 5.25 , Progesterone; 1.14 \pm 0.93 , Estrogen; 51.10 \pm 37.68 and Cortisol; $147.70 \pm 63.57$ observed in HIV seronegaetive with malaria infection ( $<<0.05$, in each case). The mean $( \pm$ SD) $2.59 \pm 1.90$ Testosterone serum concentration observed in symptomatic HIV stage 11 with malaria was significantly lower than the mean $( \pm \mathrm{SD})$ Testosterone 3.37 \pm 2.24 concentration observed in HIV seronegative with malaria infection $(\mathrm{p}<0.05)$. However, the mean $( \pm \mathrm{SD})$ Proactin; $9.33 \pm 4.67$ serum concentration observed in symptomatic HIV stage 11 with malaria compared with $10.33 \pm 3.90$ in HIV seronegative with malaria infection showed similar statistical values $(\mathrm{p}>0.05)$.

Mean $( \pm \mathrm{SD})$ serum concentration of Progesterone; 2.05 \pm 1.39 , Estrogen; 54.66 \pm 23.92 and Cortisol $205.56 \pm 135.24$ in symptomatic HIV stage 11 with malaria infection were significantly higher compared with the mean $( \pm \mathrm{SD})$ value of Progesterone 1.09 \pm 1.19 , Estrogen; $31.14 \pm 18.20$ and Cortisol; $130.02 \pm 68.22$ observed in HIV seronegative without malaria infection $(\mathrm{p}<0.05$, in each case). However, there were no significant mean differences 
for LH, FSH, Testosterone and Prolactin in symptomatic HIV stage 11 with malaria compared with the HIV seronegative without malaria ( $\mathrm{p}<0.05$, in each case).

The mean $( \pm \mathrm{SD})$ in LH; 9.72 $\pm 6.93, \mathrm{FSH} ; 7.91 \pm 5.17$ and Prolactin 10.33 \pm 3.90 , serum levels found in symptomatic HIV stage 11 without malaria were significantly similar to the value in LH; $9.33 \pm 6.06, \mathrm{FSH}, 8.54 \pm 5.25$ and Prolactin; $8.49 \pm 3.25$ observed in HIV seronegative with malaria infection ( $<<0.05$, in each case). However, the mean $( \pm \mathrm{SD})$ of the serum levels of Progesterone; $2.63 \pm 1.57$, Estrogen; $66.79 \pm 19.83$ and Cortisol; $226.70 \pm 122.53$ observed in symptomatic HIV stage 11 without malaria were significantly higher than the values observed in Progesterone; $1.14 \pm 0.93$, Estrogen 51.10 \pm 37.68 and Cortisol; $147.70 \pm 63.57$ in HIV seronegetive with malaria infection $(\mathrm{p}<0.05$, in each case). But, the mean $( \pm \mathrm{SD})$ serum levels of Testosterone $3.37 \pm 2.24$, observed in HIV seronegative with malaria infection was significantly higher than the value of Testosterone; $2.07 \pm 2.04$, observed in symptomatic HIV stage 11 without malaria $(\mathrm{p}<0.05)$.

The mean $( \pm \mathrm{SD})$ serum concentration of Progesterone; $2.63 \pm 1.57$, Estrogen; $66.79 \pm 19.83$ and Cortisol 226.90 \pm 122.53 , observed in symptomatic HIV stage 11 without malaria is significantly higher than the mean serum concentration of Progesterone $1.19 \pm 1.09$, Estrogen; $31.14 \pm 18.20$ and Cortisol; $130.02 \pm 68.22$ observed in HIV seronegative without malaria infection $(\mathrm{p}<0.05$, in each case). But, the mean $( \pm \mathrm{SD})$ serum concentration of FSH; 7,91 \pm 5.17 and Testosterone; $2.07 \pm 2.04$ observed in symptomatic HIV stage 11 without malaria were significantly lower than the mean values of FSH; $11.53 \pm 7.58$ and Testosterone; $4.80 \pm 1.75$ observed in HIV seronegative without malaria infection ( $\mathrm{p}<0.05$, in each case). However, the mean $( \pm \mathrm{SD})$ mean $( \pm \mathrm{SD})$ serum concentration of LH; $9.72 \pm 6.93$ and Prolactin; $10.33 \pm 3.90$ observed in symptomatic HIV stage 11 without malaria were not significantly different compared with the values in LH; $9.56 \pm 7.16$ and Prolactin; $9.39( \pm 3.34)$, observed in HIV seronegative without malaria infection $(\mathrm{p}>0.05)$.

The mean $( \pm \mathrm{SD})$ serum concentration of FSH $8.54 \pm 5.25$ observed in HIV seronegative with malaria was significantly lower compared with the mean value of FSH $11.33 \pm 7.58$ observed in HIV seronegative without malaria infection $(\mathrm{p}<0.05)$. But, the mean $\pm(\mathrm{SD})$ concentration of Estrogen; $51.10 \pm 31.68$ observed in HIV seronegative with malaria was found to be significantly higher than the mean value $31.14 \pm 18.20$ of Estrogen observed in HIV seronegative without malaria $(\mathrm{p}<0.05)$. However, mean $( \pm \mathrm{SD})$ serum concentration of LH, Progesterone, Testosterone, Prolactin and Cortisol compared between HIV seronegative with and without malaria infection showed similar statistical values ( $\mathrm{p}>0.05$, in each case).

\section{Discussion}

There was significantly higher LH level observed in this study, in symptomatic HIV stage 11 with malaria compared with symptomatic HIV stage 11 without malaria. This implies that malaria co-infection with HIV has a stimulatory effect on the release of LH in these participants. The observation agrees with the report by the previous researchers that reported increase serum LH in HIV infection (Burgoyne and Tan, 2008). The higher increase in malaria co-infection confirms that effect of malaria has induced profound increase in the release of the hormone from the endocrine glands into the general circulation.

Also, the study observed higher value of FSH on symptomatic HIV stage 11 with malaria compared with those without malaria infection. This may be as a result of stimulatory effect of HIV-Malaria co-infection on the release of FSH from the endocrine glands. This high incidence of FSH in malaria infection may the report of Lauferet al (2006), that HIV - related Immunosuppression increases the effect of clinical malaria disease. Increase serum FSH observed in this study has also been reported in HIV infected subjects by previous researchers (Villetteet al, 1990).

Lauferet al, (2006) reported in his recent study that HIV infection increases the rate of clinical malaria disease. In this study, high level of Testosterone was observed in symptomatic HIV stage 11 with malaria compared with symptomatic HIV stage 11 without malaria. This finding agrees with the Lauferet al, (2006) report. Leserman (2008) have observed in his recent researchers that increased Cortisol levels were released in stressful events. So, HIV-Malaria co- infection which is very stressful occurrence causes the release of Cortisol in symptomatic HIV infection with malaria found in this study. On the other hand, increased levels of Estrogen levels were observed in the groups. But, a slightly lower value was observed in symptomatic HIV stage 11 with malaria. This implies that malaria infection with HIV has an inhibitory effect on Estrogen release into the circulation.

Finally, the study hence concludes that HIV infection actually increases the rate of malaria infection in symptomatic HIV (stage11). Also, malaria infection was observed to significantly affect the secretion of LH, FSH, Testosterone and Cortisol levels from the endocrine glands in symptomatic HIV stage 11. On the other hand, malaria infection was observed to significantly inhibit the release of Progesterone, Prolactin and Estrogen levels from the endocrine glands in symptomatic HIV stage 11. 


\section{References}

[1]. Brugh VM, Lipshultz LI (2004). Male factor infertility: evaluation and management. Med. Clin. North Am.88 (2): $367-385$.

[2]. Burgoyne RW, Tan DH (2008). Prolongation and quality of life for HIV-infected adults treated with high active antiretroviral therapy (HAART): a balancing act. J. Antimicrob. Chemother.61 (3): 469-473.

[3]. Corcoran, C. and S. Grinspoon (1999). Treatments for wasting in patients with the acquired immunodeficiency syndrome diagnosis and treatment of endocrine disorders in the HIV-infected patient. New England Journal of Medicine 340 (22): 1740-1750.

[4]. Douek DC, Roederer M, Koup RA (2009). Emerging concepts in the immunopathogenesis of AIDS. Annu. Rev. Med. 60: 471-484.

[5]. Grover A, Smith CE, Gregory M, Cyr D G, Sairam M R, Hermo L (2005). Effects of FSH receptor deletion on epididymal tubules and sperm morphology, numbers, and motility. MolReprod Dev. 72(2):135-144.

[6]. Hirsh A (2003). "Male subfertility. BMJ327 (7416): 669-672.

[7]. Laufer MK (2006). Impact of HIV-associated immunosuppression on malaria infection and disease in Malawi. J Infect Dis. 193:872-878.

[8]. Leserman J (2008). Role of depression, stress and trauma in HIV disease progression. Psychosomatic Medicine 70: 539-545.

[9]. Mendis K, Sina B, Marchesini P, Carter R (2001). The neglected burden of Plasmodium vivax malaria (PDF). Am J Trop Med Hyg64 (1-2 Suppl): 97-106.

[10]. Onyenekwe C.C, Ukibe N, Mehdu S.C, Ilika A., Aboh N., Ofiaeli. N. Ezeani N, Onochie A (2007). Prevalence of malaria co -infection in HIV-infected individual in a malaria endemic area of south easther Nigeria J. vector Borne Dis 44: 250-254.

[11]. Prasanthai V, Sunthornyothin S, Phothongkum P, Suankratay C (2007). Prevalence of adrenal insufficiency in critically ill patients with AIDS. J Med Assoc Thai 90:1768-1774.

[12]. Roof RL, Hall ED (2000). Gender differences in acute CNS trauma and stroke: neuroprotective effects of estrogen and progesterone J. Neurotrauma17 (5): 367-388.

[13]. UNAIDS (2008). Report on the global AIDS epidemic. UNAIDS.

[14]. Van Den Boogaard, E.; Vissenberg, R.; Land, J. A.; Van Wely, M.; Van Der Post, J. A. M.; Goddijn, M.; Bisschop, P. H. (2011). Significance of (sub)clinical thyroid dysfunction and thyroid autoimmunity before conception and in early pregnancy: A systematic review. Human Reproduction Update 17 (5): 605-619.

[15]. VilletteJM, BourinP, DoinelC, Mansour I, FietJ, BoudouP, DreuxC, Roue R, DebordM, Levi F (1990). Circadian variations in plasma levels of hypophyseal, adrenocortical and testicular hormones in men infected with human immunodeficiency virus. J ClinEndocrinolMetab. 70:572-577.

[16]. Whitten SJ, Nangia AK, Kolettis PN (2006). Select patients with hypogonadotropichypogonadism may respond to treatment with clomiphene citrate. FertilSteril. 86(6):1664-8.

[17]. World Health Organisation (1995). Methods of counting malaria parasites in thick blood films. Bench Aids for the Diagnosis of Malaria. $1-8$

[18]. Xiong X, Wang A, Liu G, Liu H, Wang C, Xia T, Chen X, Yang K (2006). Effects of p,p'-dichlorodiphenyldichloroethylene on the expressions of transferrin and androgen-binding protein in rat Sertoli cells. Environ Res101 (3): 334-339. 